\title{
Stress reduction in the hospital room: Applying Ulrich's theory of supportive design
}

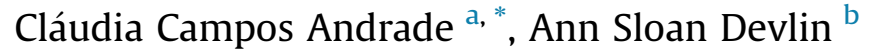 \\ ${ }^{a}$ Centro de Investigação e Intervenção Social (CIS-IUL), Instituto Universitário de Lisboa (ISCTE-IUL), Av. das Forças Armadas, 1649-026, Lisboa, Portugal \\ b Connecticut College, Psychology Department, 270 Mohegan Ave., New London, CT, 06320, USA
}

\section{A R T I C L E I N F O}

\section{Article history:}

Available online 9 December 2014

\section{Keywords:}

Hospital rooms

Design

Patients' stress

Ulrich's theory of supportive design

\begin{abstract}
A B S T R A C T
Hospital rooms may exacerbate or reduce patients' stress. According to Ulrich's (1991) theory of supportive design, the hospital environment will reduce stress if it fosters perceptions of control (PC), social support (SS), and positive distraction (PD). An experimental study was conducted to test this theory. Participants were asked to imagine a hospitalization scenario and were exposed to one of 8 lists of elements that the hospital room would provide selected to facilitate PC, SS, PD, or 1 of all the possible combinations of these elements. Results confirmed Ulrich's theory. Participants expected significantly less stress in the situations where all (or only PD and SS) elements were present. Meditational analyses confirmed that the number of elements in the hospital room affects expected stress through the perceptions of how much positive distraction and social support it is perceived to provide, but not through the perception of the level of perceived control available.
\end{abstract}

๑) 2014 Elsevier Ltd. All rights reserved.
Ulrich's (1991) theory of supportive design conceptualizes the ways in which the healthcare physical-social environment affects patients' well-being, including the reduction of stress. Ulrich proposes that healthcare physical and social environments promote well-being if they are designed to foster: a) sense of control over physical-social surroundings, b) access to social support, and c) access to positive distractions. This theory is well established in the field and is often used to describe and interpret patients' needs or to suggest strategies or approaches for achieving supportive design. As one example, the model of patient care incorporates many aspects of supportive design (Martin, Hunt, Hughes-Stone, \& Conrad, 1990). The Planetree model, dated to the late 1970s, focuses on opportunities for patients to learn about their medical situation and improve their sensory experience, through the sights, sounds, and smells in the physical environment (Planetree). The Planetree model and the theory of supportive design dovetail in terms of emphasizing access to positive distractions (e.g., artwork displayed) and social support (e.g., a 24-h visiting policy). Perceived personal control is also an element of the Planetree model through such features as open nursing stations and medical libraries, which encourage dialog about the patient's medical situation.

\footnotetext{
* Corresponding author.

E-mail addresses: claudiarcandrade@gmail.com (C.C. Andrade), asdev@conncoll. edu (A.S. Devlin).
}

Despite the prominence of Ulrich's theory, there have been no empirical tests of a model proposing that the relationship between the elements provided by the hospital physical environment and stress is mediated by perceptions of control, social support, and positive distraction. Therefore, in the current study we propose to test Ulrich's theory by investigating whether design features of an inpatient room have stress-reducing effects because they improve the perceptions of control, social support, and positive distraction.

\section{Stress in the hospital}

Stress is conceptualized as a relationship between a person and the environment that is appraised by the person as taxing or exceeding his or her resources and endangering well-being (Lazarus \& Folkman, 1984). Being in a hospital as a patient is a stressful experience (e.g., Haltman, Coakley, Annese, \& Bouvier, 2012; Tanja-Dijkstra, 2011; see Mitchell, 2003 for a review). Illness that may involve reduced physical capabilities, uncertainty, and painful medical procedures is an inevitable source of stress (e.g., Kiecolt-Glaser, Page, Marucha, MacCallum, \& Glaser, 1998). Patients also have worries that are unrelated to their health, often concerning the welfare of the family at home in the patients' absence, or the disruption of their everyday life and work obligations; these ongoing discomforts and uncertainties can generate stress (Powell \& Johnston, 2007). Johnston (1980) has shown that 
high levels of anxiety were not restricted to the immediate preoperative period, but were also experienced before admission to hospital, between admission and surgery, and following surgery. Moreover, some authors consider that hospitals do little to calm these anxieties, and many times exacerbate them (e.g., Taylor, 2011). The physical-social environments of healthcare facilities can be unsupportive of patients' well-being if they contain features that are themselves stressors (Ulrich, 1991).

The judgment that a particular person-environment relationship is stressful hinges on two major forms of appraisal. First, there is primary appraisal, through which the person evaluates the meaning and significance of a specific transaction with the environment with respect to well-being. The second evaluative process is secondary appraisal, through which the person assesses his or her own coping resources and options. The person examines what can be done to manage the situation, in particular "which coping options are available, the likelihood that a given coping option will accomplish what it is supposed to, and the likelihood that the individual can apply a particular strategy or set of strategies effectively" (Lazarus \& Folkman, 1984, p. 35). Secondary appraisals of coping options and primary appraisals of what is at stake interact with each other in shaping the degree of stress and the strength and quality (or content) of the emotional reaction. The extent to which a person believes that he or she can shape or influence a particular stressful person-environment relationship has a role in this process.

In particular, an unfamiliar and uncontrollable hospital physical environment might be appraised as harmful and demanding, thus causing stress. For example, multiple-bed rooms may contribute to loss of privacy and personal control, noise, and the enforced company of others (Larsen, Larsen, \& Birkelund, 2013). But if patients judge that they have adequate coping resources and environmental options to deal with the situation - for example, if they can find refuge both inside and outside the hospital room - stress may be reduced.

In sum, the (unnecessary) stress patients experience in the hospital should be reduced as much as possible. According to Ulrich's theory of supportive design (1991), a supportive health care physical environment is one way of reducing stress responses and fostering patients' well-being. More specifically, stress may be reduced environmentally or even prevented by providing positive resources/conditions in terms of control, distraction, and social interactions (see Fig. 1).

\section{The healing potential of the physical environment}

Research has demonstrated that the quality of the physical environment of hospital rooms contributes to patients' well-being (e.g., Devlin \& Arneill, 2003), but little attention has been paid to the modeling processes involved in this relationship (Andrade,

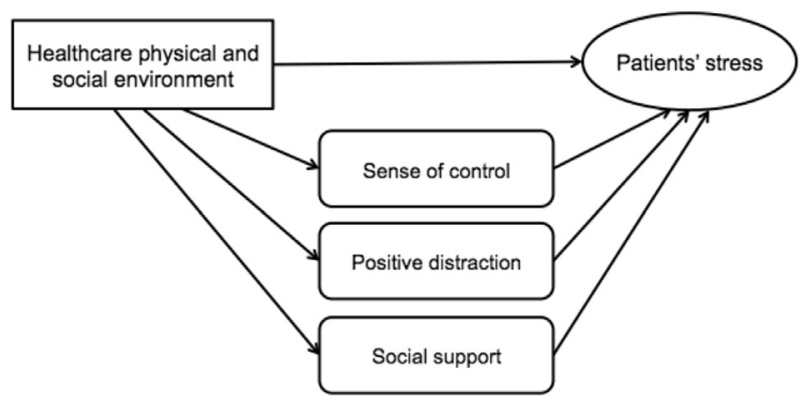

Fig. 1. Adaptation of Ulrich's theory of supportive design.
Lima, Fornara, \& Bonaiuto, 2012). However, interventions in the healthcare physical environment will be more effective if the intervening mediating and moderating variables that affect the success of those interventions are known. Thus, the present study seeks to identify some of the modeling variables involved in the relationship between the quality of hospital rooms and patients' well-being. Particularly, this study will test the mediating role of perceived control, social support, and positive distraction (Ulrich 1991).

\subsection{Perceived personal control}

Personal control is the opportunity to have an impact on aspects of one's life, and to exert mastery (Fisher, 1990). The feeling of control over the environment is a mechanism that is likely involved in the relationship between environmental options and well-being (or stress reduction) (see Lee \& Brand, 2005; for a good summary of sense of control as it relates to the physical environment). Namely, a sense of control is related to opportunities to modify or alter aspects of the environment (Allen \& Greenberger, 1980; Huang, Robertson, \& Chang, 2004).

In hospitals, the routine that is established may render patients helpless; they cannot effect change. As inpatients, people experience a loss of control related to almost every aspect of their daily lives. Patients usually do not decide what and when to eat and when to receive visitors; they have little opportunity to leave the inpatient area, are limited in their range of activities, and do not have control over their surrounding physical environment. In some illnesses, such as cancer, patients' bodies are literally out of control; for these patients, opportunities to exert control over the physical environment may help combat the sense of helplessness they feel. To counter that feeling of helplessness, Huisman, Morales, Van Hoof, and Kort (2012) recommend what they call "self-supporting systems" to enable the patient to control many aspects of the room, from the position of the bed and the degree of natural light to the acoustical environment (television, music). When patients are limited, these restrictions extend to family members and staff (Suter \& Baylin, 2007). Thus, addressing this lack of control is critical in creating a supportive environment for patients and their social system.

For patients in a cancer infusion center, control over light, adjusting window blinds, the temperature of the infusion chair, and access to food were among the variables important to patients (Peter Hourihan, personal communication, 2012). Suter and Baylin (2007) indicate that control can be enhanced when patients are able to choose their own art. Examples related to stress and the lack of control or choice include the level of noise (Hagerman et al., 2005), the unattractiveness of the room (e.g., Dijkstra, Pieterse, \& Pruyn, 2008), or the presence of a television that is not under personal control (Ulrich, Simons, \& Miles, 2003).

The American Institute of Architects (2006) has recommended single-room occupancy as the minimum standard for a range of healthcare facilities, which - among other benefits - increases patients' privacy, patients' control over personal information and characteristics of the environment, an opportunity to rest, and an opportunity to discuss their needs with family members, friends, and staff (Chaudhury, Mahmood, \& Valente, 2005). Despite the advantages of single room occupancy, there is still opportunity to further decrease patients' stress in the physical environment.

\subsection{Positive distraction}

The model of patient-centered care emphasizes using positive distractions (Frampton, Charmel, \& Planetree, 2008; Planetree). In the health care environment, the beneficial role played by what is 
known as positive distraction is well documented (Malenbaum, Keefe, Williams, Ulrich, \& Somers, 2008; McCaul \& Malott, 1984; Ulrich, 1984, 1991, 2009; Ulrich, Berry, Quan, \& Parish, 2010; Ulrich \& Gilpin, 2003; Ulrich, Lunden, \& Etinge, 1993; Ulrich et al., 2003; Ulrich et al., 2008). Positive distractions help people attend to stimuli other than their own discomfort and anxiety. Positive distractions include static stimuli such as reading material, photographs, and representational posters or paintings of nature. Active stimuli such as music, companion animals, and people laughing also have the potential to provide positive distraction. In distraction theory, pain is considered to deplete attentional resources, and viewing nature has been shown to restore attention after executive attention is depleted (Berman, Jonides, \& Kaplan, 2008). Simulated nature has been found to have stress-reducing effects similar to those of being in nature (Berman et al., 2008; Kjellgren \& Buhrkall, 2010). Ulrich et al. (2003) found that viewing a nature video positively affected physiological measures such as pulse rate when having blood drawn at a blood donor bank. With regard to content, research has repeatedly demonstrated the preference for representational scenes of nature (Cusack, Lankston, \& Isles, 2010; Eisen, Ulrich, Shepley, Varni, \& Sherman, 2008; Hathorn \& Nanda, 2008; Ulrich \& Gilpin, 2003).

With regard to acoustical stimuli, crying babies and ringing phones can disturb patients (Minckley, 1968). Conversely, music has been suggested to reduce stress (Cooke, Chaboyer, \& Hiratos, 2005); the Continuous Ambient Relaxation Environment (C.A.R.E.) Channel (broadcast on television with accompanying images of nature) has been created to provide music specifically designed for healthcare environments, often at 60 beats per minute (bpm) (Mazer, 2010; Mazer \& Smith, 1999).

\subsection{Social support}

In a potentially unfamiliar and stressful environment, having the social support of others can ameliorate stress (Bolger \& Amarel, 2007). Increasingly, family members make hospital visits, and the space has to be designed to accommodate their presence. Social support is widely acknowledged as a psychosocial factor that influences health outcomes (e.g., Berkman, Glass, Brissette, \& Seeman, 2000; Cohen, 1988; Uchino, 2009), and it is recommended by the Mayo Clinic as a way to create a sense of belonging, increase a sense of self worth, and increase feelings of security (Mayo clinic staff). There is some indication that very high levels of social support can ameliorate the effects of stress (Kornblith et al., 2001), and social support has been linked to a variety of physical health outcomes (Uchino, 2009). In addition, social support has been linked to reduced stress and depression in hospital staff (Park, 2007).

Uchino (2009) discusses the difference between perceived and received social support, with perceived social support linked to access to social support, whereas received social support deals with the actual receipt of such support services and resources. In this research, we are interested in factors that influence received support, that is, in the physical spaces that could accommodate those capable of providing support.

\section{Hypotheses}

Our hypothesis is that the as number of environmental elements - facilitating control, distraction, or social support - in a hospital room increases, the level of perceived stress will decrease. We further hypothesize that perceptions of control, positive distraction, and possibilities for social support provided by the room will explain (mediate) the link between the number of elements in the room and patients' well-being. Moreover, we expect that the room elements categorized within each category (perceived control, positive distraction, and social support) will be more highly associated with the respective mediator than with the others.

\section{Method}

\subsection{Participants and design}

Participants were 217 students, split between Portugal $(n=142)$ and the United States $(n=75)$. In the total sample, there were 91 (42.1\%) women and 125 (57.9\%) men, and the mean age was 20.99 years $(S D=5.48$ years $)$.

In the Portuguese sample, there were 29 women (20.6\%) and 112 men $(79.4 \%)$, and the mean age was 22.04 years $(S D=6.54$ years). In the American sample, there were 62 women (82.7\%) and 13 men $(17.3 \%)$, and the mean age was 19.07 years $(S D=1.08)$. Sixty-six (88.0\%) American participants were White, 5 (6.7\%) were Black or African American, and 4 (5.3\%) were Asian. In terms of ethnicity, 2 (2.7\%) participants identified as Spanish, Hispanic or Latino. Portuguese respondents were not asked their race.

In each country, the experiment employed a between-subjects design with participants randomly assigned to one of eight possible conditions consisting of an illustration of a hospital room accompanied by a set of amenities and features. This procedure has been shown to accurately simulate real environments (Bateson \& Hui, 1992; Stamps, 1993).

\subsection{Stimulus materials}

The stimulus materials consisted of a floor plan of a standard hospital room and eight different descriptions (i.e., lists) of the available room amenities. The floor plan (common across all conditions) showed a single room with a private bathroom. The single room had a bed, two bedside tables, a closet with hangers, and a window; the bathroom had a sink, a toilet, and a shower (see Fig. 2). A single-occupancy room was used to avoid the confounding aspects of roommates.

The descriptions were developed using four steps: 1) first, design characteristics of hospital rooms the literature has associated with stress reduction were listed (e.g., plants, TV, light and temperature regulation); 2) a pilot study was carried out in which 39 adults in the United States (primarily surveyed at a train station) with experience of being in a hospital were asked a) how much they thought those characteristics are important for hospitals to provide, and b) whether those characteristics are usually provided in hospitals. Additional design characteristics were included from open-ended responses these participants provided. From that pool of items, 3) some of the items were selected to create the scenarios. Items were selected based on one of the following criteria: a) features that were perceived as important but that usually are not provided (e.g., space for friends and family), b) features that were suggested by several participants (e.g., refrigerator), or c) features about which there is scientific evidence of an impact on stress (e.g., plants). Finally, 4) items were grouped by the authors in terms of being potentially (and more specifically) related to facilitating social support, positive distraction, or perceived control. There were four items each associated with facilitating social support (SS), positive distraction (PD), or perceived control (PC).

To manipulate social support we listed the following features: space and chairs for family and friends, Internet (e.g., email, Skype), bed side phone, and sleeper sofa for family and friends. To manipulate positive distraction we listed: TV with 40 channels and DVD/VCR combo, space to put photographs from family and friends, plants, and paintings of nature. Finally, to manipulate perceived control we listed the following features: lighting adjustable by 
Please pay attention to the layout of the private room with a private bathroom where you would stay and carefully read which amenities are provided.

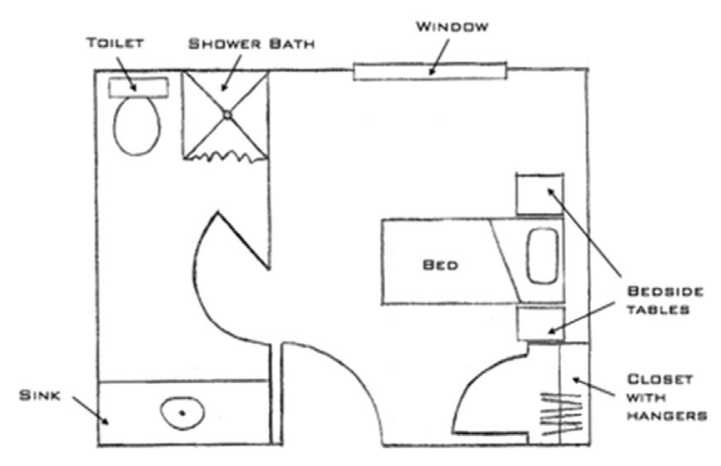

In addition to the basic features labeled in the plan, this room will also provide the following amenities:

- Space and chairs for family and friends

- Internet (e.g., email, Skype)

- Bed side phone

- Sleeper sofa for family and friends

- TV with 40 channels and DVD/NCR combo

- Space to put photographs of family and friends

- Plants

- Paintings of nature

- Lighting adjustable by patients

- Temperature adjustable by patients

- Windows that patients can open

- Refrigerator

After 1:30 this page will advance automatically. Please read it carefully.

Fig. 2. Room for perceived control condition. Note: The image of the floor plan contained $454 \times 258$ pixels.

patients, temperature adjustable by patients, windows openable by patients, and refrigerator (see Table 1). To ascertain that the elements in the categories were reliable, the final list of elements was tested on 72 Portuguese university students. After presenting definitions of perceived control, positive distraction, and social support (see Table 2), we presented the list of 12 room elements one at a time, and asked participants how much - in their opinion - each element would produce each outcome, on a scale where " 1 " was not at all and "4" was "a lot".

A series of repeated measures analyses of variance (ANOVA) were then performed to determine whether each of the 12 room elements produced more of the psychological effect it was meant to produce (i.e., social support, positive distraction, and perceived control) than did the others. As predicted, participants rated all the elements selected to produce social support as producing more social support than positive distraction and perception of control (all $p s<.001$ ); and rated the all the elements selected to produce perceived control as producing more perceived control than positive distraction and social support (all $p s<.001$ ). Participants also rated three of the elements selected to produce positive distraction as producing more positive distraction than perception of control and social support. Photographs from family and friends were perceived as producing as much positive distraction as social support $(p=.254)$. However, based on the study of Master et al. (2009), we decided to categorize the photographs as a "social support" element. The Master et al. study showed that simply viewing a loved one's picture could reduce the experience of physical pain (and social support was not confounded with distraction).

In sum, there were eight experimental conditions: three conditions with the elements in the separate clusters (SS, PD, or PC); three conditions from adding elements across clusters (SS + PD, $\mathrm{SS}+\mathrm{PC}, \mathrm{PD}+\mathrm{PC}$ ); one condition including all 12 elements $(\mathrm{SS}+\mathrm{PD}+\mathrm{PC})$; and the control condition, which included no elements (see Table 1).

\subsection{Measures}

Perceived stress was measured using Spielberger's 20-item State Anxiety Inventory (Spielberger, Gorsuch, \& Lushane, 1970) that indicates the level of stress or anxiety an individual is feeling at the present moment. Scores range from 20 to 80, with higher scores reflecting greater anxiety. A sample item is "I am tense," which is measured from 1 ("not at all") to 4 ("very much so"). Before answering these questions, participants read the following: "Imagine you are recovering in the hospital room just described in the text you read and illustrated in the plan you saw. Imagining that, please tell us how you think you would feel in that situation. Read each statement and select the appropriate response to indicate how you think you would feel in that hospital room. There are no right or wrong answers. Do not spend too much time on any one statement but give the answer which seems to describe your feelings best."

Perceived positive distraction provided by the physical environment was measured through eight items adapted from scales used to measure fascination (Hartig, Korpela, Evans, \& Gärling, 1997; Laumann, Gärling, \& Stormark, 2001) (e.g., "In this room my attention is drawn to interesting things"). To measure the perceived level of control over the physical environment, we used seven items from scales used in other studies (Lee \& Brand, 2005; Veitch \& Gifford, 1996) (e.g., "I can control the physical features of my hospital room"). Finally, to measure the perceived social support provided by physical environment we created six items (e.g., "This hospital room provides good opportunities for engaging in social activities"). All the items were answered on a Likert scale from 1 (strongly disagree) to 5 (strongly agree).

The 21 questions dealing with the categories of social support, positive distraction, and perceived control were mixed to reduce the possibility that respondents would form hypotheses about the underlying purpose of the study. The list of questions was preceded by this statement: "Now please think about the amenities that your room would provide (as described in the text). Thinking about that, please select the number that best describes the extent to which you agree or disagree with the following statements:"

To ascertain the extent to which participants had absorbed and paid attention to the material, we used a free recall question and asked them to recall all the amenities provided by the room, separating the items by a comma. Following this question, they were asked to indicate "yes" or "no" which items on a list provided were actually shown on the floor plan. At the end of the survey, demographic questions included gender, age, class year, and major. 
Table 1

Experimental conditions and associated elements.

\begin{tabular}{|c|c|c|}
\hline Condition & Elements & $\begin{array}{l}\text { Number } \\
\text { of elements }\end{array}$ \\
\hline $\begin{array}{l}\text { 1) Elements potentially } \\
\text { related to social support }\end{array}$ & $\begin{array}{l}\text { - Space and chairs for family and } \\
\text { friends } \\
\text { - Internet (e.g., email, Skype) } \\
\text { - Bed side phone } \\
\text { - Sleeper sofa for family and friends }\end{array}$ & 4 \\
\hline $\begin{array}{l}\text { 2) Elements potentially } \\
\text { related to positive } \\
\text { distractions }\end{array}$ & $\begin{array}{l}\text { - TV with } 40 \text { channels and DVD/ } \\
\text { VCR combo } \\
\text { - Space to put photographs of } \\
\text { family and friends } \\
\text { - Plants } \\
\text { - Paintings of nature }\end{array}$ & 4 \\
\hline $\begin{array}{l}\text { 3) Elements potentially } \\
\text { related to perceived } \\
\text { control }\end{array}$ & $\begin{array}{l}\text { - Lighting adjustable by patients } \\
\text { - Temperature adjustable by } \\
\text { patients } \\
\text { - Windows that patients can open } \\
\text { - Refrigerator }\end{array}$ & 4 \\
\hline $\begin{array}{l}\text { 4) Social support }+ \text { positive } \\
\text { distraction }\end{array}$ & $\begin{array}{l}\text { - Space and chairs for family and } \\
\text { friends } \\
\text { - Internet (e.g., email, Skype) } \\
\text { - Bed side phone } \\
\text { - Sleeper sofa for family and friends } \\
\text { - TV with } 40 \text { channels and DVD/ } \\
\text { VCR combo } \\
\text { - Space to put photographs of } \\
\text { family and friends } \\
\text { - Plants } \\
\text { - Paintings of nature }\end{array}$ & 8 \\
\hline $\begin{array}{l}\text { 5) Social } \\
\text { support }+ \text { perceived } \\
\text { control }\end{array}$ & $\begin{array}{l}\text { - Space and chairs for family and } \\
\text { friends } \\
\text { - Internet (e.g., email, Skype) } \\
\text { - Bed side phone } \\
\text { - Sleeper sofa for family and friends } \\
\text { - Lighting adjustable by patients } \\
\text { - Temperature adjustable by } \\
\text { patients } \\
\text { - Windows that patients can open } \\
\text { - Refrigerator }\end{array}$ & 8 \\
\hline $\begin{array}{l}\text { 6) Positive } \\
\text { distraction }+ \text { perceived } \\
\text { control }\end{array}$ & $\begin{array}{l}\text { - TV with } 40 \text { channels and DVD/ } \\
\text { VCR combo } \\
\text { - Space to put photographs of } \\
\text { family and friends } \\
\text { - Plants } \\
\text { - Paintings of nature } \\
\text { - Lighting adjustable by patients } \\
\text { - Temperature adjustable by } \\
\text { patients } \\
\text { - Windows that patients can open } \\
\text { - Refrigerator }\end{array}$ & 8 \\
\hline 7) All elements & $\begin{array}{l}\text { - Space and chairs for family and } \\
\text { friends } \\
\text { - Internet (e.g., email, Skype) } \\
\text { - Bed side phone } \\
\text { - Sleeper sofa for family and } \\
\text { friends- Lighting adjustable by } \\
\text { patients } \\
\text { - Temperature adjustable by } \\
\text { patients } \\
\text { - Windows that patients can open } \\
\text { - Refrigerator } \\
\text { - TV with } 40 \text { channels and DVD/ } \\
\text { VCR combo } \\
\text { - Space to put photographs of } \\
\text { family and friends } \\
\text { - Plants } \\
\text { - Paintings of nature }\end{array}$ & 12 \\
\hline $\begin{array}{l}\text { 8) No elements (control } \\
\text { condition) }\end{array}$ & & 0 \\
\hline
\end{tabular}

American participants were also asked their race, and whether they were of Spanish, Hispanic, or Latino origin or descent. The final demographic question asked respondents to indicate how many times they had been hospitalized.

\subsection{Procedure}

The study was conducted online using Qualtrics. Participants gave their informed consent and were told that the experiment sought to examine "perceptions of hospital rooms." A scenario was presented asking participants to imagine that they had been hospitalized with symptoms of acute appendicitis. They were asked to imagine having strong abdominal pain, vomiting, and fever and then going to the emergency room of a hospital for testing, where doctors decide the appendix needs to be removed. Participants are told that this hypothetical operation was a success but that they need to stay in a hospital room for three days to recover.

Next, participants were exposed to a floor plan with one of the eight amenity lists. Text at the bottom of the screen stated: "After 1:30 min this page will advance automatically. Please read it carefully." In all conditions, participants were exposed to the same floor plan of the hospital room into which they were to imagine having been admitted. For all conditions, the image of the floor plan contained $454 \times 258$ pixels. However, depending on the experimental condition, the scenario text described a different kind and number of physical design features available. In the control condition there was no reference to the availability of any physical design features. After viewing the floor plan and list of amenities, participants answered the questions comprising the dependent variables (social support, positive distraction, and perceived control, and stress), followed by a manipulation check and demographic items. After participants answered the questions, a screen with the debriefing statement was provided.

\section{Results}

Two hundred and ninety-three students opened the survey online. Excluding the 76 students that did not answer any questions from the STAI or any questions at all, 217 participants were retained.

In order to detect the organization of the items created to assess the perceptions of control, social support, and positive distraction promoted by the environment in specific dimensions, we ran a factor analysis using the method of Principal Axis Factoring with Varimax Rotation. From the initial solution we eliminated the items with loadings lower than 0.5 , and those with factor loadings equal to or higher than .40 on more than one factor. Consequently we choose a three component solution, by keeping only the factors with eigenvalues higher than 1 . These factors explain $65.76 \%$ of the variance. As predicted, the first factor aggregated six items referring to perceived control; the second factor is composed of six items and captures social support; and the third factor includes four items and represents the positive distraction dimension. Afterwards, we computed three composite measures based on this three-factor solution. The Cronbach's alpha values for the composite variables "perceived control," "social support," and "positive distraction" were $.91, .90$, and .91 , respectively.

An exploratory factor analysis (Principal Axis Factoring with Varimax Rotation) of the 20 items measuring anxiety was performed. We eliminated 2 items with loadings lower than 0.40 , and we kept one factor that accounted for $37.35 \%$ of the total variance. Responses to the remaining 18 items were scaled (Cronbach's $\alpha=.92$ ), with higher numbers reflecting higher anxiety.

Then data were analyzed for univariate outliers, defined as cases on which the absolute value of the standardized score in each of the four variables (perceived control, social support, positive distraction, and stress) was between 1.5 and 3 times the interquartile range. This resulted in 14 participants being dropped. 
Table 2

Definitions of perceived control, positive distraction, and social support used to assess the reliability of the elements in the categories.

\begin{tabular}{|c|c|c|}
\hline Construct & Definition & Sources consulted \\
\hline Perceived control & $\begin{array}{l}\text { "To have control over situations is a basic human need. In particular, we need to feel } \\
\text { that we have control over the environment that surrounds us. We define perception } \\
\text { of control" over the physical environment as the feeling that we can change, modify } \\
\text { or transform the environment according to our needs. We feel control when we feel } \\
\text { we can personalize a space (ex: to use a decorative object), we can decide on its } \\
\text { environmental characteristics (e.g., turn on or off the light) or on who can enter and } \\
\text { remain in that space (e.g., single vs. multiple-bed room). For example, we have } \\
\text { complete control over the environment of our bedroom in our house, but no (or very } \\
\text { little) control over the environment of our dentist's waiting room". }\end{array}$ & $\begin{array}{l}\text { Evans and McCoy (1998); Lee and Brand (2005); Veitch } \\
\text { and Gifford (1996) }\end{array}$ \\
\hline Positive distraction & $\begin{array}{l}\text { "The physical environment has the ability to induce positive or negative emotions to } \\
\text { decrease or increase the stress. For example, the presence of plants or an aquarium } \\
\text { in a room attracts attention, distracts and induces relaxation; as opposed to an } \\
\text { empty room. An environment with elements that positively capture one's attention } \\
\text { we call an environment that promotes "positive distraction." }\end{array}$ & $\begin{array}{l}\text { Hartig et al. (1997); Laumann et al. (2001); Ulrich (1991, } \\
\text { 1992) }\end{array}$ \\
\hline Social support & $\begin{array}{l}\text { "When one has social support it feels there is a group of people (friends, family, } \\
\text { others) who care about and can help in case of need. The physical environment can } \\
\text { facilitate or hinder the possibility to establish or to use a network of social support. } \\
\text { For example, being in a country distant from our family/friends makes it difficult, } \\
\text { but having a phone helps. Another example might be: a public garden without trees } \\
\text { (shadows) or benches hinders the access to social support, while a public garden } \\
\text { with trees and benches facilitates social support. We call the ability of an } \\
\text { environment to promote such responses 'social support'." }\end{array}$ & Cohen (1988; 2004); Sommer and Ross (1958) \\
\hline
\end{tabular}

\subsection{Manipulation check}

Conditions in which perception of control was manipulated and conditions in which it was not were compared in terms of levels of perceived control provided by the environment, and the same was done regarding social support and positive distraction. As predicted, participants in conditions in which positive distraction was manipulated (i.e., in which the four elements to promote positive distraction were presented alone or with four other elements) perceived the environment as more distracting $(M=3.43, S D=.76$, $n=69$ ) than did participants in the control condition (no elements) $(M=1.79, S D=0.63, n=37, p<.001)$, and than in the conditions in which positive distraction was not manipulated (i.e., in which four or eight other elements were presented) $(M=2.87, S D=0.90$, $p<.001, n=75$ ). No significant differences in terms of perception of opportunity for positive distraction were found between conditions in which positive distraction was manipulated and the condition in which participants were exposed to all elements $(M=3.79$, $S D=0.71, n=21$ ).

Also according to the expectations, participants in conditions in which social support was manipulated (i.e., in which the four elements to promote social support were presented alone or with other four elements) perceived the environment as better promoting social support $(M=4.63, S D=0.42, n=73)$ than did participants in the control condition (no elements) $(M=3.41$, $S D=1.14, n=37, p<.001)$, and than in the conditions in which social support was not manipulated (i.e., in which four or eight other elements were presented $)(M=3.99, S D=0.80, p<.001$, $n=71$ ). No significant differences in terms of perception of opportunity for social support were found between conditions in which social support was manipulated and the condition in which participants were exposed to all elements $(M=4.92, S D=0.14$, $n=21$ )

Finally, participants in conditions in which perception of control was manipulated (i.e., in which the four elements to promote perception of control were presented alone or with four other elements) perceived more control over the environment $(M=3.30$, $S D=0.86, n=72$ ) than did participants in the control condition (no elements $)(M=2.32, S D=0.92, n=21, p<.001)$, and less perceived control than did participants that were exposed to all elements $(M=3.95, S D=0.75, n=37, p=.019)$. However, no significant differences were found between the conditions in which perception of control was manipulated and the conditions in which perception of control was not manipulated (i.e., in which four or eight other elements were presented $)(M=3.38, S D=0.94, n=72)$, suggesting that this construct may have been less successfully operationalized than the others, a possibility that is discussed later as a limitation of the research.

\subsection{Stress}

Levels of stress across conditions were analyzed (see Fig. 3). Across conditions, stress tends to increase (lowest to highest) in the following order: all amenities; social support \& positive distraction; social support; social support \& perceived control; positive distraction \& perceived control; positive distraction; no amenities; and perceived control.

Stress is significantly higher in a room with no amenities than in a room with all amenities $(p=.009)$ or with elements to promote social support and positive distraction $(p=.019)$, and the same is true for a room with elements that promote perceived control ( $p=.007$, and $p=.014$, respectively). Irrespective of the conditions, results show that the more elements presented in the hospital room $(0,4,8$ or 12$)$, the less the stress expected $(r=-.264$, $p<.001)$.

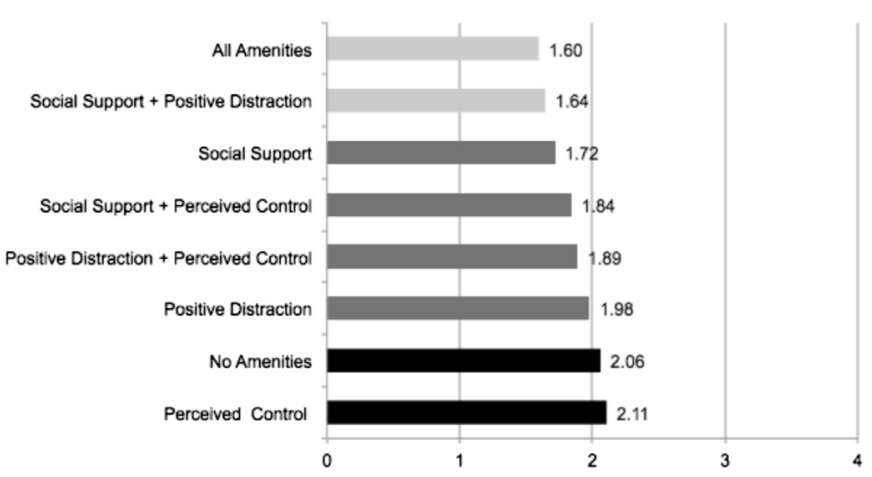

Fig. 3. Level of expected stress by condition ( $0=$ not al all, $4=$ very much). Means in light grey and black bars are significantly different from each other. 


\subsection{Mediation analyses}

Table 3 presents the descriptive statistics and the correlations between the indicators used. All the correlations are weak to moderate, including the correlations between the indicators of the different latent variables, which indicate that they are measuring different constructs, avoiding any multicollinearity issues.

In order to check the construct validity of the proposed measurement model we conducted a Confirmatory Factor Analysis (CFA) (Bollen, 1989). In this model, we specified four conceptual latent variables (i.e., perception of control, social support, positive distraction, and anxiety) that were allowed to correlate. In order to guarantee the statistical identification of the models, the factorial loading of one of the indicators of each latent variable were constrained at 1.00 . Results showed a good fit to the data: $\chi^{2}(521$, $N=202)=1147.240, p<.001, \chi^{2} / \mathrm{df}=2.202, C F I=.848, G F I=.706$, $R M S E A=.077 ; p(R M S E A \leq 0.05)<.001$. Moreover, factorial loadings were high on their respective factor (loadings varying from 35 to $.88)$.

Anxiety was negatively correlated with perception of control $(r=-.31)$, positive distraction $(r=-.45)$, and social support $(r=-.56)$. Perception of control was positively correlated with social support $(r=.47)$, and positive distraction $(r=.66)$, and positive distraction was positively correlated with social support $(r=.57)$. All correlations were significant $(p<.001)$. These results were compared to an alternative measurement model in which all items loaded on a general factor, meaning that all items measure only one latent variable. Results for this model showed a poor fit to the data, $\chi^{2}(527, N=202)=2576.864, p<.001, \chi^{2} / \mathrm{df}=4.890$, $C F I=.503, G F I=.408$, RMSEA $=.139 ; p($ RMSEA $\leq .05)<.001$. Thus, the proposed measurement model fits better than the alternative one, $\Delta \chi^{2}(6, N=202)=1429.624, p<.001$, supporting the construct validity of the proposed measurement model.

To test the hypothesis that the relationship between the number of elements in the room and stress is mediated by the perception that the room provides control, social support, and positive distraction, we followed the procedures commonly recommended for the analysis of mediation using structural equation models (e.g., Kenny \& Judd, 1984). Our measure of stress (STAI) has a large number of items (i.e., 18); for that reason, we created four parcels (two with 4 items each, and two with 5 items each) by aggregating together items with higher and lower loadings.

Results show that the total effect of number of elements/amenities in the hospital room on stress (corresponding to the effect of number of elements before taking into account the control, social support, and positive distraction in the model) is significant ( $\beta=-.28, p<.001)$, which means that the higher the number of elements provided, the lower the level of stress. As one can see in Fig. 4, the relationship between the number of items and perceived control, positive distraction, and social support, are positive and significant, i.e., a greater number of elements in the room implies greater perception of control $(\beta=.45, p<.001)$, social support $(\beta=.55, p<.001)$, and positive distraction $(\beta=.62, p<.001)$ provided by the environment. On the other hand, the effect of the social support $(\beta=-.47, p<.001)$ and positive distraction $(\beta=-.22, p=.047)$ on stress is significant, whereas the perception of control does not reliably predict the reduction of stress. Finally, the direct effect of the number of elements on stress is not significant, suggesting that that effect could be mediated. Of greater importance for the mediation test, the analysis of the decomposition of the effects of the number of elements on stress indicates that only the perception of social support (Mediated effect $=.26$; $Z_{\text {Sobel }}=-4.25, p<.001$, one-tailed) and the perception of positive distraction (Mediated effect $=.14 ; Z_{\text {Sobel }}=-1.94, p=.026$, onetailed) mediate this relationship.

The four independent variables accounted for $30 \%$ of the variance in stress and analyses of the goodness-of-fit indices for the proposed model show a good fit to the data: $\chi^{2}(180$, $N=202)=298.753, p<.001, \chi^{2} / \mathrm{df}=1.66, C F I=.96, G F I=.88$, $R M S E A=.06$. These results demonstrate the construct validity of the measures we used to test our predictions.

We removed perception of control from the model because perception of control does not have a significant effect on stress. In the resulting model, three independent variables accounted for $30 \%$

Table 3

Means, standard deviations, and correlation matrix of the variables.

\begin{tabular}{|c|c|c|c|c|c|c|c|c|c|c|c|c|c|c|c|c|c|c|c|c|c|}
\hline & Mean (SD) & (1) & (2) & (3) & (4) & (3) & (6) & (7) & (8) & (9) & (10) & (11) & $(12)$ & (13) & (14) & (15) & $(16)$ & (17) & (18) & (19) & (20) \\
\hline \multicolumn{22}{|l|}{ Stress } \\
\hline Stress 1 (1) & $1.07(0.53)$ & & & & & & & & & & & & & & & & & & & & \\
\hline Stress $2(2)$ & $2.07(0.57)$ & .74 & & & & & & & & & & & & & & & & & & & \\
\hline Stress 3 (3) & $1.93(0.57)$ & .72 & .77 & & & & & & & & & & & & & & & & & & \\
\hline Stress 4 (4) & $1.79(0.51)$ & .76 & .75 & .82 & & & & & & & & & & & & & & & & & \\
\hline \multicolumn{22}{|c|}{ Perceived control } \\
\hline PC $1(5)$ & $3.52(1.15)$ & -.34 & -.28 & -.29 & -.28 & & & & & & & & & & & & & & & & \\
\hline PC $2(6)$ & $3.32(1.23)$ & -.27 & -.29 & -.25 & -.25 & .49 & & & & & & & & & & & & & & & \\
\hline PC $3(7)$ & $3.03(1.20)$ & -.18 & -.21 & -.19 & -.17 & .58 & .61 & & & & & & & & & & & & & & \\
\hline PC $4(8)$ & $3.09(1.22)$ & -.18 & -.18 & -.17 & -.15 & .57 & .63 & .72 & & & & & & & & & & & & & \\
\hline PC $5(9)$ & $3.30(1.19)$ & -.19 & -.19 & -.21 & -.20 & .60 & .62 & .66 & .70 & & & & & & & & & & & & \\
\hline PC $6(10)$ & $3.02(1.17)$ & -.16 & -.17 & -.19 & -.12 & .57 & .67 & .66 & .71 & .73 & & & & & & & & & & & \\
\hline \multicolumn{22}{|c|}{ Positive distraction } \\
\hline PD 1 (11) & $3.00(1.27)$ & -.22 & -.31 & -.27 & -.24 & .37 & .33 & .39 & .44 & .39 & .40 & & & & & & & & & & \\
\hline PD 2 (12) & $2.43(1.19)$ & -.22 & -.28 & -.24 & -.25 & .45 & .44 & .47 & .47 & .48 & .49 & .65 & & & & & & & & & \\
\hline PD 3 (13) & $3.33(1.26)$ & -.26 & -.23 & -.23 & -.21 & .41 & .41 & .41 & .47 & .39 & .45 & .73 & .61 & & & & & & & & \\
\hline PD 4 (14) & $3.09(1.05)$ & -.20 & -.26 & -.18 & -.16 & .30 & .32 & .29 & .29 & .41 & .37 & .50 & .51 & .46 & & & & & & & \\
\hline PD 5 (15) & $2.98(1.31)$ & -.29 & -.33 & -.31 & -.30 & .38 & .43 & .43 & .40 & .39 & .43 & .68 & .66 & .68 & .50 & & & & & & \\
\hline PD 6 (16) & $2.94(1.27)$ & -.40 & -.44 & -.41 & -.40 & .52 & .51 & .43 & .46 & .48 & .53 & .65 & .60 & .70 & .54 & .68 & & & & & \\
\hline \multicolumn{22}{|c|}{ Social support } \\
\hline SS $1(17)$ & $4.32(0.90)$ & -.36 & -.35 & -.34 & -.39 & .33 & .25 & .20 & .19 & .26 & .17 & .22 & .22 & .29 & .29 & .33 & .38 & & & & \\
\hline SS $2(18)$ & $4.03(1.03)$ & -.45 & -.43 & -.46 & -.43 & .46 & .42 & .44 & .45 & .45 & .40 & .51 & .40 & .49 & .31 & .47 & .53 & .59 & & & \\
\hline SS 3(19) & $4.41(0.91)$ & -.40 & -.36 & -.36 & -.39 & .35 & .31 & .24 & .27 & .32 & .25 & .29 & .28 & .35 & .31 & .36 & .39 & .77 & .69 & & \\
\hline SS $4(20)$ & $4.08(1.15)$ & -.41 & -.37 & -.39 & -.40 & .36 & .38 & .32 & .31 & .40 & .29 & .41 & .40 & .44 & .34 & .47 & .49 & .70 & .73 & .75 & \\
\hline \multicolumn{22}{|c|}{ Number of elements (21) } \\
\hline & $4.11(2.70)$ & -.26 & -.23 & -.25 & -.25 & .39 & .35 & .41 & .41 & .37 & .30 & .52 & .47 & .55 & .35 & .56 & .44 & .37 & .49 & .42 & .54 \\
\hline
\end{tabular}

Note: Correlation matrix's diagonal was omitted. All ps $<.001$. 


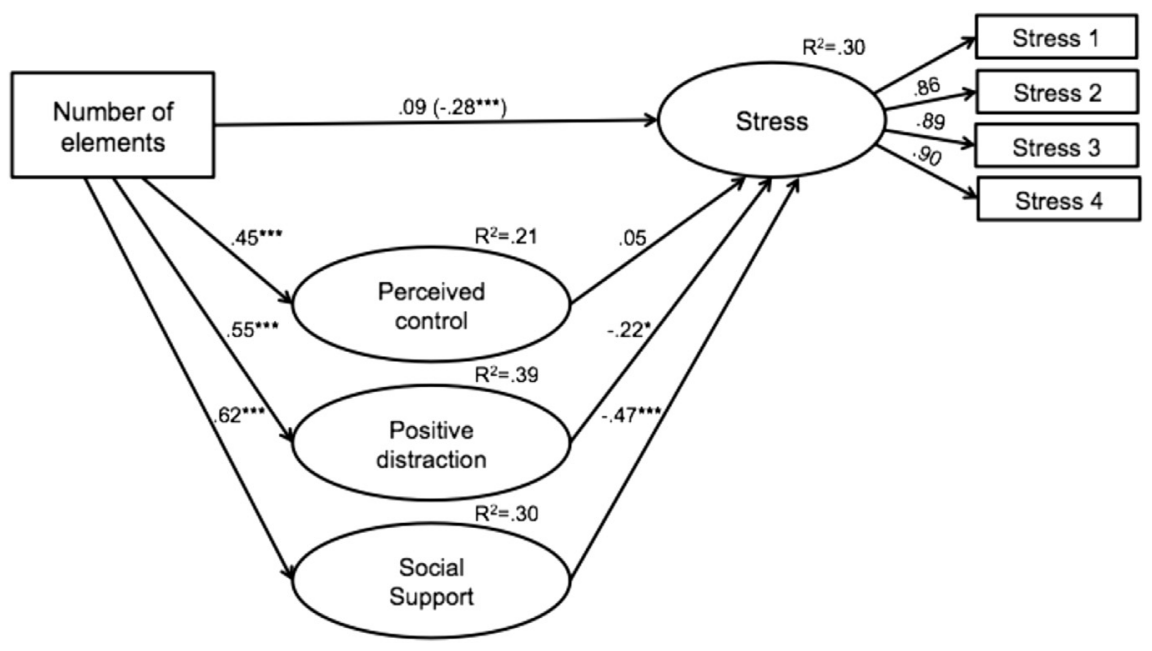

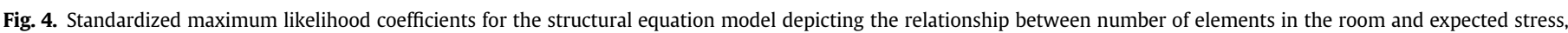

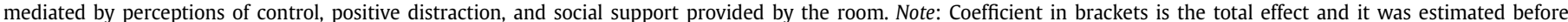

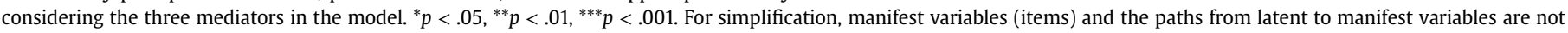
shown; and manifest variables' error terms, and correlations between mediating latent variables were omitted.

of the variance in stress and the goodness-of-fit improved: $\chi^{2}(85$, $N=202)=155.154, p<.001, \chi^{2} / \mathrm{df}=1.83, C F I=.97$, GFI $=.90$, $R M S E A=.06\left(\Delta \chi^{2}(95, N=202)=143.599, p<.001\right)$.

\section{Discussion}

The main goal of the present research was to contribute to a better understanding of the ways through which the healthcare physical environment impacts patients' well-being. In the theory of supportive design, Ulrich (1991) proposed that a hospital environment will alleviate patients' stress if it provides them a sense of control, positive distraction, and possibilities of social support. However, this theoretical model has never been fully empirically tested. We proposed to do that through an experimental study, by testing the general hypothesis that the more favorable elements present in a hospital room the less stressful the experience will be perceived, and that this relationship between hospital room elements and the expected well-being is mediated by perceptions of control (PC), positive distractions (PD), and social support (SS). The assumption is that the unknown and uncontrollable hospital environment might be appraised as harmful and demanding, but if the patient evaluates that he or she has the adequate coping resources and options to deal with it, those might help ease the situation. In particular, stress might be reduced if patients feel the opportunity to influence aspects of their hospital room and to adapt its conditions to their needs.

The study used an experimental between-subjects design in which participants were randomly assigned to one of eight conditions. All participants were presented with a hypothetical hospitalization scenario and exposed to the same hospital room plan, accompanied by one of eight possible elements lists (no elements; 4 PC elements; 4 PD elements; 4 SS elements; 4 PC +4 PD elements; 4 PC +4 SS elements; 4 PD +4 SS elements; or 4 PC +4 $\mathrm{PD}+4$ SS elements). Results showed that no elements in the room or the presence of PC elements resulted in significantly more expected stress than was true for the situations where all elements were present (PC, PD, SS) or where only PD and SS elements were present. These results suggest that having more elements in the room is desirable, except if those elements provide perceived control (PC).

Direct (unmediated) and indirect (mediated) relationships involving the number of elements in a hospital room; perceptions of control, positive distraction, and social support; and expected stress were tested through structural equation modeling. Results confirmed the hypothesis that the hospital room environment affects expected stress through the perceptions of how much positive distraction and social support it is perceived to provide, but not through perception of the level of perceived control available. Specifically, elements in a hospital room predict the perception of control, positive distraction, and social support; however, only positive distraction and social support reduce expected stress. In other words, in hospital rooms with higher numbers of elements/ amenities, patients expect to feel less stress because they expect to have conditions for positive distraction and social support.

Overall, evidence was found for Ulrich's theoretical model. The fact that the perception of control did not predict stress-reduction may be related to the elements used to manipulate this construct, namely, lighting and temperature adjustable by patients, windows that patients can open, and a refrigerator. Actually, the manipulation check showed no significant differences in terms of perceived control between the conditions in which the control elements were used and the conditions in which they were not used. Thus, it is possible that these elements were considered somewhat common or standard in a hospital room, and that perceptions of control depend more on other kind of amenities such as room service (i.e., food) on demand or a whiteboard that presents the patient's plan of care.

Another possible explanation is that people in a hospital may not want to have control. On the one hand, it has been shown that the provision of education and support to surgical patients has a positive effect on their physical and psychological well-being, which can be explained by the fact that it increases and maintains the patients' feelings of control (Breemhaar \& van den Borne, 1991). However, there is evidence that patients have different needs for information and care, and that some patients demand more medical information than do others (e.g., Ong et al., 1999). According to Breemhaar and van den Borne (1991), it is possible that increasing the level of perceived control can lead to an increase in stress if control brings with it demands that patients do not wish to meet or that patients (think they) cannot meet, or if the situation does not allow the exercise of control. In the case of our study, participants may have thought that adjusting lighting, temperature, and windows is the kind of activity they do not need to care about in a short hospital stay, such as the one described in the 
present study. More studies are needed on what the hospital physical environment should provide to promote sense of control, and on what kind of environmental control patients want and need.

Patients may not know they can manipulate aspects of the environment such as temperature, and when patients arrive from surgery they may be more interested in pain management than in environmental manipulation. Researchers need to better understand to what extent patients receive a kind of "operations knowledge" for their inpatient room, including the content, form, and timing of such communication. For example, during a question-and-answer session at the 2013 EDRA inaugural fall symposium "The Landscape of Accountable Care," Barry Rabner, President and CEO of the Princeton HealthCare System, said that the television and education system remote control in the patient's room at the new University Medical Center of Princeton at Plainsboro was so complicated that even he did not understand it (personal communication, October 11, 2013). If we want patients to use amenities that provide a sense of control, we must help them understand how to use such controls.

\section{Future research and final comments}

To our knowledge, this study was the first to test Ulrich's theory of supportive design. The results obtained confirmed Ulrich's theory, but need further exploration in real settings, because being ill produces physiological and psychological conditions that may have an important impact on patients' needs and perceptions. Moreover, one cannot overlook the fact that the participants in this study were students, with an average age of 21 , which, in principle, means limited hospital experience. On average, participants had been hospitalized 1.04 times $(S D=1.28$; minimum $=0$; maximum $=8$ ). Thus, future research should use an older sample with various levels of experience in health care settings. Despite the limitations of an experimental study, it was demonstrated that the simple exposure to a description of a hospital room (and what it provides) communicates a message about the stress that can be expected. In particular, we found that design features perceived as nurturing social support and providing positive distractions may ease the anxiety associated with hospitalization.

Cultural differences have been neglected in research on healthcare environments (one exception is a study by Devlin, Nasar, \& Cubukcu, 2014). However, the sociocultural context in which the hospital physical environment is embedded may change how its physical features affect people (Winkel, Saegert, \& Evans, 2009), for example by setting different levels of expectations, or relating to cultural values. In fact, even the actual healthcare environment varies between cultures and countries - for example, new hospitals in the US are likely to have mostly single rooms, which does not happen in Portugal. Although the separated samples are small, we used multi-group analysis to explore whether the psychological process going from the number of favorable elements in the room to stress occurs in the same way for both American and Portuguese participants, and the results indicated that the results remained virtually the same. Nevertheless, the cultural context should be considered in future studies on healthcare design.

In this study we were less interested in the room elements themselves, but more in the psychological states they produce that result in well-being (specifically the ones theorized by Ulrich, 1991). Certainly many other room features would be capable of affecting patients' well-being than the ones we used to manipulate possibilities of control, distraction, and social support. From the standpoint of intervention, we believe that if we better understand what kind of patients' psychological needs are affected by the physical environment of the hospital, it will be easier to decide which particular elements that environment should include.
In practical terms, social support and positive distraction have the potential to reduce the stress patients feel in the inpatient room. Financially, providing aspects of positive distraction (e.g., art, music, television) is less costly than expanding the inpatient room to accommodate more visitors. Yet the movement toward single room occupancy in the United States (AIA, 2006) provides the opportunity for designers to think about configurations and furnishings that welcome visitors. These include such ideas as window seats that are wide enough to truly double as a bed and chairs for visitors that fold up and can be stored on wall hooks when not in use. Outside of the room itself, lounges for families and visitors also send the message that they are welcome, which ultimately benefits the patient.

\section{Acknowledgments}

This research was supported by a PhD Grant (SFRH/BD/43452/ 2008) from the Portuguese Foundation for Science and Technology awarded to the first author.

\section{References}

Allen, V. L., \& Greenberger, D. B. (1980). Destruction and perceived control. In A. Baum, \& J. Singer (Eds.), Advances in environmental psychology (Vol. 2, pp. 85-209). Hillsdale, NJ: Erlbaum.

American Institute of Architects. (2006). http://www.aia.org/aah/gd/hospcons.

Andrade, C. C., Lima, M. L., Fornara, F., \& Bonaiuto, M. (2012). Users' views of hospital environmental quality: Validation of the Perceived Hospital Environment Quality Indicators (PHEQIs). Journal of Environmental Psychology, 32, 97-111. http://dx.doi.org/10.1016/j.jenvp.2011.12.001.

Bateson, J. E. G., \& Hui, M. K. (1992). The ecological validity of photographic slides and videotapes in simulating the service setting. Journal of Consumer Research. 19, 271-281.

Berkman, L. F., Glass, T., Brissette, I., \& Seeman, T. E. (2000). From social integration to health: Durkheim in the new millennium. Social Science and Medicine, 51, 843-857. http://dx.doi.org/10.1016/S0277-9536(00)00065-4.

Berman, M. G., Jonides, J., \& Kaplan, S. (2008). The cognitive benefits of interacting with nature. Psychological Science, 19, 1207-1212. http://dx.doi.org/10.1111/ j.1467-9280.2008.02225.x.

Bolger, N., \& Amarel, D. (2007). Effects of social support visibility on adjustment to stress. Experimental evidence. Journal of Personality and Social Psychology, 92, 458-475. http://dx.doi.org/10.1037/0022-3514.92.3.458.

Bollen, K. (1989). Structural equations with latent variables. Hoboken, NJ: Wiley Interscience.

Breemhaar, B., \& van den Borne, H. W. (1991). Effects of education and support for surgical patients: The role of perceived control. Patient Education and Counseling, 18, 199-210.

Chaudhury, H., Mahmood, A., \& Valente, M. (2005). Advantages and disadvantages of single-versus-multiple-occupancy patient rooms in acute care environments: A review and analysis of the literature. Environment \& Behavior, 37, 760-786. http://dx.doi.org/10.1177/0013916504272658.

Cohen, S. (1988). Psychosocial models of the role of social support in the etiology of physical disease. Health Psychology, 7, 269-297.

Cohen, S. (2004). Social relationships and health. The American Psychologist, 59, 676-684. http://dx.doi.org/10.1037/0003-066X.59.8.676.

Cooke, M., Chaboyer, W., \& Hiratos, M. A. (2005). Music and its effect on anxiety in short waiting periods: A critical appraisal. Journal of Clinical Nursing, 14, 145-155. http://dx.doi.org/10.1111/j.1365-2702.2004.01033.x.

Cusack, P., Lankston, L., \& Isles, C. (2010). Impact of visual art in patient waiting rooms: Survey of patients attending a transplant clinic in Dumfries. Journal of the Royal Society of Medicine Short Reports, 1(6), 52. http://dx.doi.org/10.1258/ shorts.2010.010077.

Devlin, A. S., \& Arneill, A. (2003). Health care environments and patient outcomes: A review of the literature. Environment \& Behavior, 35, 665-694. http:// dx.doi.org/10.1177/0013916503255102.

Devlin, A. S., Nasar, J. L., \& Cubukcu, E. (2014). Students' impressions of psychotherapists' offices: Cross-cultural comparisons.

Dijkstra, K., Pieterse, M. E., \& Pruyn, A. T. H. (2008). Stress-reducing effects of indoor plants in the built healthcare environment: The mediating role of perceived attractiveness. Preventive Medicine, 47, 279-283. http://dx.doi.org/10.1016/ j.ypmed.2008.01.013.

Eisen, S. L., Ulrich, R. S., Shepley, M. M., Varni, J. W., \& Sherman, S. (2008). The stressreducing effects of art in pediatric health care: Art preferences of healthy children and hospitalized children. Journal of Child Health Care, 12, 173-190. http://dx.doi.org/10.1177/1367493508092507.

Evans, G. W., \& McCoy, J. M. (1998). When buildings don't work: The role of architecture in human health. Journal of Environmental Psychology, 18, 85-94. http://dx.doi.org/10.1006/jevp.1998.0089. 
Fisher, R. J. (1990). The social psychology of intergroup and international conflict resolution. New York: Springer-Verlag.

Frampton, S., Charmel, P., \& Planetree. (2008). Putting patients first: Best practices in patient-centered care (2nd ed.). Hoboken, NJ: Jossey-Bass.

Hagerman, I., Rasmanis, G., Blomkvist, V., Ulrich, R. S., Eriksen, C. A., \& Theorell, T. (2005). Influence of coronary intensive care acoustics on the quality of care and physiological states of patients. International Journal of Cardiology, 98, 267-270. http://dx.doi.org/10.1016/j.ijcard.2003.11.006.

Haltman, T., Coakley, A. B., Annese, C. D., \& Bouvier, S. (2012). Exploring the sleep experiences of adult patients. Creative Nursing, 18, 135-139. http://dx.doi.org/ 10.1891/1078-4535.18.3.135.

Hartig, T., Korpela, K., Evans, G. W., \& Gärling, T. (1997). A measure of restorative quality in environments. Scandinavian Housing and Planning Research, 14, 175-194.

Hathorn, K., \& Nanda, U. (2008). A guide to evidence-based art. The Center for Health Design. http://www.healthdesign.org/sites/default/files/Hathorn_Nanda_Mar08. pdf.

Huang, Y. H., Robertson, M. M., \& Chang, K. (2004). The role of environmental control on environmental satisfaction, communication, and psychological stress: Effects of office ergonomics training. Environment and Behavior, 36 , 617-637. http://dx.doi.org/101177/0013916503262543.

Huisman, E. R. C. M., Morales, E. J., Van Hoof, J., \& Kort, H. S. M. (2012). Healing environment: A review of the impact of the physical environment. Building and Environment, 58, 70-80. http://dx.doi.org/10.1016/j.buildenv.2012.06.016, 74.

Johnston, M. (1980). Anxiety in surgery patients. Psychological Medicine, 10, $145-152$.

Kenny, D. A., \& Judd, C. M. (1984). Estimating the nonlinear and interactive effects of latent variables. Psychological Bulletin, 96, 201-210. http://dx.doi.org/10.1037/ 0033-2909.96.1.201.

Kiecolt-Glaser, J. K., Page, G. G., Marucha, P. T., MacCallum, R. C., \& Glaser, R. (1998). Psychological influences on surgical recovery: Perspectives from psychoneuroimmunology. American Psychologist, 53(11), 1209-1218.

Kjellgren, A., \& Buhrkall, H. (2010). A comparison of the restorative effect of a natural environment with that of a simulated natural environment. Journal of Environmental Psychology, 30, 464-472. http://dx.doi.org/10.1016/ j.jenvp.2010.01.011.

Kornblith, A. B., Herndon, J. E., Zuckerman, E., Visocli, C. M., Horwitz, R. I., Cooper, M. R., et al. (2001). Social support as a buffer to the psychological impact of stressful life events in women with breast câncer. Cancer, 91, 443-454. http://dx.doi.org/10.1002/1097-0142(20010115)91:2<443::AIDCNCR1020>3.0.CO;2-Z

Larsen, L. S., Larsen, B. H., \& Birkelund, R. (2013). A companionship between strangers - The hospital environment as a challenge in patient-patient interaction in oncology wards. Journal of Advanced Nursing, 395-404. http:// dx.doi.org/10.1111/jan.12204.

Laumann, K., Gärling, T., \& Stormark, K. M. (2001). Rating scale measures of restorative components of environments. Journal of Environmental Psychology, 21, 31-44. http://dx.doi.org/10.1006/jevp.2000.0179.

Lazarus, R. S., \& Folkman, S. (1984). Stress, appraisal and coping. New York: Springer.

Lee, S., \& Brand, J. (2005). Effects of control over office workspace on perceptions of the work environment and work outcomes. Journal of Environmental Psychology, 25, 323-333. http://dx.doi.org/10.1016/j.jenvp.2005.08.001.

Malenbaum, S., Keefe, F. J., Williams, A., Ulrich, R., \& Somers, T. J. (2008). Pain in its environmental context: Implications for designing environments to enhance pain control. Pain, 134, 241-244. http://dx.doi.org/10.1016/j.pain.2007.12.002.

Martin, D. P., Hunt, J. R., Hughes-Stone, M., \& Conrad, D. A. (1990). The Planetree model hospital project: An example of the patient as partner. Hospital \& Health Services Administration, 35, 591-601.

Master, S. L., Eisenberger, N. I., Taylor, S. E., Naliboff, B. D., Shirinyan, D., \& Lieberman, M. D. (2009). A picture's worth: Partner photographs reduce experimentally induced pain. Psychological Science, 20(11), 1316-1318.

Mayo clinic staff. Social support: Tap this tool to beat stress. http://www.mayoclinic. com/health/social-support/SR00033.

Mazer, S. E. (2010). Hospital noise and the patient experience: Seven ways to create and maintain a quieter environment. http://www.healinghealth.com/ susanmazer/wp-content/uploads/2010/10/hhs_hospital_noise_whitepaper.pdf.

Mazer, S. E., \& Smith, D. (1999). Sound choices: Using music to design the environments in which you live, work, and heal. Carlsbad, CA: Hay House, Inc.

McCaul, K. D., \& Malott, J. M. (1984). Distraction and coping with pain. Psychological Bulletin, 95, 516-533. http://dx.doi.org/10.1037/0033-2909.95.3.516.
Minckley, B. B. (1968). A study of noise and its relationship to patient discomfort in the recovery room. Nursing Research, 17, 247-250.

Mitchell, M. (2003). Patient anxiety and modern elective surgery: A literature review. Journal of Clinical Nursing, 12, 806-815. http://dx.doi.org/10.1046/j.13652702.2003.00812.x.

Ong L. M., Visser, M. R, van Zurren, F. J. Rietbroek, R. C. Lammes, F. B., \& de Haes, J. C. (1999). Cancer patients' coping styles and doctor-patient communication. Psychooncology, 8(2), 155-166.

Park, K.-O. (2007). Social support for stress prevention in hospital settings. The Journal of the Royal Society for the Promotion of Health, 127, 260-264. http:/ dx.doi.org/10.1177/1466424007084066.

Planetree. "Planetree pioneers: Angelica Thieriot." Planetree. http://planetree.org planetree-pioneers/ Accessed 24.09.14.

Powell, R., \& Johnston, M. (2007). Hospitalization in adults. In S. Ayers, A. Baum, C. McManus, S. Newman, K. Wallston, J. Weinman, et al. (Eds.), Cambridge handbook of psychology, health \& medicine (2nd ed.). (pp. 109-113). Cambridge: Cambridge University Press.

Sommer, R., \& Ross, H. (1958). Social interaction on a geriatrics ward. International Journal of Social Psychiatry, 4(2), 128-133. http://dx.doi.org/10.1177| 002076405800400207.

Spielberger, C. D., Gorsuch, R. L., \& Lushene, R. E. (1970). Manual for the State-Trait Anxiety Inventory. Palo Alto, CA: Consulting Psychologists Press.

Stamps, A. E. (1993). Simulation effects on environmental preference. Journal of Environmental Management, 38, 115-132. http://dx.doi.org/10.1177| 08854129922092630

Suter, E., \& Baylin, D. (2007). Choosing art as a complement to healing. Applied Nursing Research, 20, 32-38.

Tanja-Dijkstra, K. (2011). The impact of bedside technology on patients' well-being Health Environments Research and Design Journal, 5(1), 43-51.

Taylor, S. E. (2011). Health psychology (8th ed.). New York: McGraw Hill.

Uchino, B. N. (2009). Understanding the links between social support and physical health: A life-span perspective with emphasis on the separability of perceived and received support. Perspectives on Psychological Science, 4, 236-255. http:/ dx.doi.org/10.1111/j.1745-6924.2009.01122.x.

Ulrich, R. S. (1984). View through a window may influence recovery from surgery. Science, 224, 420-421. http://dx.doi.org/10.1126/science.6143402.

Ulrich, R. S. (1991). Effects of interior design on wellness: Theory and recent scientific research. Journal of Health Care Interior Design, 3, 97-109.

Ulrich, R. S. (1992). How design impacts wellness. Healthcare Forum Journal, 35 $20-25$.

Ulrich, R. S. (2009). Effects of viewing art on health outcomes. In S. B. Frampton, \& P. A. Charmel (Eds.), Putting patients first: Best practices in patient-centered care (2nd ed.). (pp. 129-149). San Francisco, CA: Jossey-Bass.

Ulrich, R. S., Berry, L. L, Quan, X. \& Parish, J. T. (2010). A conceptual framework for the domain of evidence-based design. Health Environments Research \& Design Journal, 4(1), 95-114.

Ulrich, R. S., \& Gilpin, L. (2003). Healing arts: Nutrition for the soul. In S. B. Frampton, L. Gilpin, \& P. A. Charmel (Eds.), Putting patients first: Designing and practicing patient-centered care (pp. 117-146). San Francisco, CA: JosseyBass.

Ulrich, R. S., Lunden, O., \& Etinge, J. L. (1993, October). Effects of exposure to nature and abstract pictures on patients recovery from heart surgery. In Society for Psychophysiological Research, 33rd Annual Meeting, Rottach-Egern, Germany (pp. S1-S7).

Ulrich, R. S., Simons, R. F., \& Miles, M. A. (2003). Effects of environmental simulations and television on blood donor stress. Journal of Architectural and Planning Research, 20(1), 38-47.

Ulrich, R. S., Zimring C. M., Zhu, X., DuBose, J., Seo, H., \& Choi, Y, (2008). A review o the research literature on evidence-based healthcare design. Health Environments Research \& Design, 1(3), 61-125.

Veitch, J. A., \& Gifford, R. (1996). Assessing beliefs about lighting effects on health, performance, mood, and social behavior. Environment and Behavior, 28, 446-470. http://dx.doi.org/10.1177/0013916596284002.

Winkel, G., Saegert, S., \& Evans, G. W. (2009). An ecological perspective on theory, methods, and analysis in environmental psychology: advances and challenges. Journal of Environmental Psychology, 29, 318-328. http://dx.doi.org/10.1016 j.jenvp.2009.02.005. 